\title{
RASPA DA MANDIOCA PARA CODORNAS EM POSTURA
}

\author{
[Cassava scrapings in diets of quails laying]
}

\author{
Adriana Aparecida Pereira ${ }^{1}$, Diogo Augusto Ferreira ${ }^{2}$, Dirceu Neutzling Griep Júnior ${ }^{3}$, Carolyny Batista \\ Lima $^{1}$, Andressa Sousa de Moura ${ }^{2}$, Dorgival Morais de Lima Júnior ${ }^{1 *}$ \\ ${ }^{1}$ Universidade Federal de Alagoas, Campus Arapiraca. Arapiraca-AL. \\ ${ }^{2}$ Universidade Federal de Alagoas, Centro de Ciências Agrárias. Rio Largo-AL. \\ ${ }^{3}$ Universidade Federal de Sergipe, Campus São Cristóvão. São Cristóvão/SE.
}

RESUMO - Objetivou-se com esse estudo avaliar o efeito de níveis crescentes de inclusão da raspa da mandioca em rações de codornas japonesas, na fase de postura, sobre desempenho, qualidade dos ovos e viabilidade econômica das dietas. Foram utilizadas 200 codornas fêmeas (Coturnix japonica) distribuídas em 25 gaiolas. Cinco dietas experimentais foram formuladas com níveis crescentes $(0,6,12,18$ e $24 \%)$ de inclusão de raspa da mandioca na matéria seca da ração. Foram realizadas coletas para analise das características de qualidade dos ovos e desempenho das aves. A inclusão da raspa de mandioca na dieta proporcionou comportamento quadrático $(\mathrm{P}<0,05)$ para o consumo de ração e conversão alimentar por dúzia de ovos. A percentagem de postura foi de $93,55 \%$ e não foi influenciada $(\mathrm{P}>0,05)$ pelos níveis de raspa. A inclusão da raspa de mandioca não influenciou $(\mathrm{P}>0,05)$ na percentagem do albúmen, percentagem de gema, percentagem de casca nem na cor da gema. A inclusão de $24 \%$ de raspa de mandioca proporcionou menores custos com arraçoamento. Recomenda-se a inclusão de até $12 \%$ de raspa de mandioca na ração de codornas em postura. Níveis mais elevadas (18 e 24\%) promovem aumento do consumo de ração, piora na conversão alimentar e redução do peso do ovo.

Palavras-Chave: alimento alternativo; fontes de amido; Manihot.

\begin{abstract}
The objective of this study was to evaluate the effect of increasing levels of inclusion of cassava scrapings in Japanese quail rations in the laying, on performance, egg quality and economic viability of diets. 200 female quails were used (Coturnix japonica) distributed in 25 cages. Five experimental diets were formulated with increasing levels $(0,6,12,18$ and 24\%) of inclusion of cassava scrapings in the dry matter. Samples were collected for analysis of the quality characteristics of eggs and Japanese quail performance. The inclusion of cassava scrapings in the diet provided quadratic effect $(\mathrm{P}<0.05)$ for feed intake and feed conversion per dozen eggs. The laying percentage was $93.55 \%$ and was not influenced $(\mathrm{P}>0.05)$ by scraping levels. The inclusion of cassava scrapings did not affect $(\mathrm{P}>0.05)$ in the percentage of albumen, yolk percentage, percentage of bark and yolk color. The inclusion of $24 \%$ of cassava yielded lower costs with feeding. It is recommended to include up to $12 \%$ of cassava scrapings in Japanese quail feed. Higher levels (18 and 24\%) promote increased feed intake, feed conversion worsening and reduced egg weight.
\end{abstract}

Keywords: Alternative food; sources of starch; Manihot.

\footnotetext{
* Autor para correspondência. E-mail: juniorzootec@yahoo.com.br Recebido: 17 de fevereiro de 2016.

Aceito para publicação: 11 de maio de 2016.
} 


\section{INTRODUÇÃO}

Entre os sistemas de exploração de animais, a avicultura é um dos setores que melhor representa a tendência de crescimento nos próximos anos. A produção de ovos de codornas também vem merecendo destaque recentemente, devido à precocidade na produção, alta produtividade, pequeno espaço para implantação logística das granjas, baixo investimento e rápido retorno do capital empregado.

A competição com a dieta humana, no entanto, está constantemente elevando os custos dos ingredientes utilizados nas dietas das aves e onerando a carne e os ovos produzidos por esses animais. Mediante os elevados custos com ingredientes tradicionais, fontes alternativas de amido e proteína têm sido constantemente testadas em ração para frangos de corte e galinhas poedeiras, não sendo, esse cenário, diferente na coturnicultura.

Uma fonte de amido com elevada disponibilidade é a raiz da mandioca (Manihot esculenta). Este alimento apresenta, segundo Rostagno et al. (2011) altos teores de amido $(67,85 \%)$ e baixos teores de fibra $(5,42 \%)$, proteína $(2,47 \%)$ e gordura $(0,59)$. Além disso, a raiz é obtida da planta da mandioca, um vegetal amplamente distribuído nas zonas tropicais do globo.

A raiz da mandioca apresenta como limitantes de uso na dieta das aves seu elevado teor de umidade e a presença de glicosídeos cianogênios. Esses glicosídeos, após injúria mecânica, originarão o ácido cianídrico, um composto extremamente tóxico e com potencial para matar aves, mesmo em doses baixas. Todavia, tanto o excesso de umidade como a presença de cianeto podem ser eliminados da raiz após desintegração e exposição solar por 24 horas (Chauynarong et al., 2009).

A raspa de mandioca pode ser incluída na dieta de aves de corte em até $10 \%$ da matéria seca total. O aumento desse nível provocou piora na conversão alimentar dos frangos (Nascimento et al., 2005; Ferreira et al., 2012; Ferreira et al., 2014). Na dieta de poedeiras, a inclusão da raspa da mandioca proporcionou comportamento linear negativo para consumo de ração, conversão alimentar e produção de ovos (Costa et al., 2009). A inclusão dos subprodutos da mandioca também proporcionou redução da coloração da gema quando participou de mais de $50 \%$ da dieta de poedeiras (Cruz et al., 2006). Em codornas japonesas, Silva et al. (2003) encontraram valores de energia metabolizável aparente $(\mathrm{kcal} / \mathrm{kg})$ de 3.329 para farinha de mandioca.

Por outro lado foi constatado por Silva et al. (2012) que codornas metabolizam os alimentos de forma diferente dos frangos e de galinhas poedeiras.

O presente estudo foi realizado para avaliar níveis crescentes de inclusão de raspa da mandioca em rações de codornas japonesas na fase de postura sobre o desempenho produtivo, qualidade dos ovos e análise econômica das dietas.

\section{MATERIAL E MÉTODOS}

O experimento foi conduzido no setor de Avicultura da Universidade Federal de AlagoasCampus Arapiraca. O município de Arapiraca encontra-se entre às coordenadas geográficas, latitude de $-09^{\circ} 42^{\prime}$ ' $97^{\prime \prime}$ e longitude de $-36^{\circ} 41^{\prime} 82^{\prime \prime}$, estando a $325 \mathrm{~m}$ acima do nível do mar. A temperatura e a umidade relativa interna do galpão foram registradas diariamente através de termohigrômetro digital. Durante o período da pesquisa, a temperatura média máxima e mínima foi de $29,5^{\circ} \mathrm{C}$ e $20,6^{\circ} \mathrm{C}$, respectivamente, enquanto que a umidade relativa média máxima foi de $57,7 \%$ e a média mínima, de 51,4\%.

Foram utilizadas 200 codornas fêmeas (Coturnix japonica) adquiridas da granja Fujikura ${ }^{\circledR}$, como um dia de idade. As aves foram criadas em pinteiros adaptados, com temperatura controlada através de lâmpadas, onde permaneceram até atingirem 21 dias de idade. As codornas foram alimentadas com ração para fase de cria e recria, à base de milho e farelo de soja, conforme preconizado por Rostagno et al. (2011).

Aos 21 dias de idade, as aves foram debicadas e transferidas para gaiolas de postura, de arame galvanizado, onde permaneceram durante todo o período experimental. De 21 dias de idade até o aparecimento do $1^{\circ}$ ovo, por volta dos 40 dias de idade, as codornas foram alimentadas com a ração de recria. Ao iniciar a produção, as aves consumiram ração de postura, conforme exigência estabelecida por Rostagno et al. (2011).

Aos 120 dias de idade, as codornas foram distribuídas em um delineamento em blocos casualizados em 25 gaiolas, com oito aves cada, onde permaneceram por três ciclos de 21 dias.

As raspas da mandioca (RM) utilizadas no presente estudo foram produto do descasque manual da mandioca da cultivar Campina, com um ano de idade, adquiridas em casas de farinha da região. As $\mathrm{RM}$ eram compostas pela casca, entrecasca e raiz aderida a casca.. Inicialmente, as raspas foram lavadas e postas para secar ao sol por 48 horas, sendo revolvidas constantemente para uma secagem uniforme. Durante a secagem as raspas forma revolvidas constantemente para uma secagem 
uniforme. Após secagem o material foi triturado em maquina trituradora de grãos, utilizando peneira de $2 \mathrm{~mm}$ e incorporada à ração das codornas.

Foram utilizadas cinco rações experimentais, sendo uma referência à base de farelo de soja e milho, e as outras com 6, 12, 18 e 24\% de inclusão de raspa da mandioca nas rações. As rações experimentais foram formuladas de acordo com as recomendações de Rostagno et al. (2011), considerando-se as exigências para codornas japonesas em fase de postura, sendo, as mesmas, isoenergéticas (2.800 $\mathrm{Kcal} / \mathrm{kg}$ ) e isolisínicas $(1,23 \%)$, como exposto na Tabela 1.

Tabela 1. Composição centesimal das rações experimentais.

\begin{tabular}{|c|c|c|c|c|c|}
\hline \multirow{2}{*}{ Ingredientes } & \multicolumn{5}{|c|}{ Níveis de inclusão da RM (\%) } \\
\hline & 0 & 6 & 12 & 18 & 24 \\
\hline Milho & 49,889 & 42,709 & 35,235 & 36,994 & 29,403 \\
\hline Farelo de Soja & 39,442 & 40,051 & 40,902 & 33,276 & 34,733 \\
\hline Raspa da Mandioca & - & 6,000 & 12,000 & 18,000 & 24,000 \\
\hline Fosfato Bicálcico & 1,049 & 0,980 & 0,984 & 1,031 & 1,064 \\
\hline Calcário & 6,580 & 6,612 & 6,578 & 6,550 & 6,520 \\
\hline Óleo de Soja & 2,121 & 2,722 & 3,380 & 3,000 & 3,000 \\
\hline Sal Comum & 0,310 & 0,311 & 0,312 & 0,310 & 0,310 \\
\hline DL-Metionina & 0,387 & 0,400 & 0,411 & 0,500 & 0,500 \\
\hline Premix Vit. Postura & 0,100 & 0,100 & 0,100 & 0,100 & 0,100 \\
\hline Premix Min. Aves & 0,050 & 0,050 & 0,050 & 0,050 & 0,050 \\
\hline Cloreto de Colina & 0,040 & 0,040 & 0,040 & 0,040 & 0,040 \\
\hline L-Lisina HCL & 0,023 & 0,015 & 0,000 & 0,138 & 0,223 \\
\hline B H T & 0,010 & 0,010 & 0,010 & 0,010 & 0,010 \\
\hline L-Treonina & 0,000 & 0,000 & 0,000 & 0,000 & 0,048 \\
\hline TOTAL & 100 & 100 & 100 & 100 & 100 \\
\hline \multicolumn{6}{|c|}{ Composição Calculada } \\
\hline Energia Metabolizável (kcal/kg) & 2.800 & 2.800 & 2.800 & 2.800 & 2.800 \\
\hline Proteína Bruta (\%) & 22,323 & 22,186 & 22,129 & 20,510 & 19,429 \\
\hline Fibra Bruta $(\%)$ & 3,063 & 3,136 & 3,215 & 3,150 & 3,134 \\
\hline Gordura $(\%)$ & 5,383 & 5,643 & 5,947 & 5,439 & 5,233 \\
\hline Fósforo Total (\%) & 0,544 & 0,546 & 0,539 & 0,523 & 0,511 \\
\hline Cálcio (\%) & 2,922 & 1,505 & 2,922 & 2,922 & 2,922 \\
\hline Sódio & 0,146 & 0,146 & 0,146 & 0,146 & 0,146 \\
\hline Lisina Total (\%) & 1,233 & 1,233 & 1,233 & 1,233 & 1,233 \\
\hline Metionina Total (\%) & 0,699 & 0,706 & 0,713 & 0,777 & 0,759 \\
\hline Met. + Cist. Total (\%) & 1,052 & 0,999 & 1,054 & 1,090 & 1,052 \\
\hline Triptofano Total (\%) & 0,278 & 0,279 & 0,282 & 0,258 & 0,243 \\
\hline Ácido Linoléico (\%) & 2,379 & 2,723 & 2,795 & 2,530 & 2,444 \\
\hline Arginina Total $(\%)$ & 1,502 & 1,505 & 1,514 & 1,386 & 1,305 \\
\hline Fenilalanina Total (\%) & 1,115 & 1,108 & 1,105 & 1,011 & 0,948 \\
\hline Fenil. + Tir. Total (\%) & 1,896 & 1,885 & 1,881 & 1,722 & 1,616 \\
\hline Histidina Total (\%) & 0,588 & 0,584 & 0,582 & 0,535 & 0,504 \\
\hline Isoleucina Total (\%) & 0,971 & 0,970 & 0,973 & 0,890 & 0,837 \\
\hline Leucina Total (\%) & 1,849 & 1,831 & 1,798 & 1,648 & 1,538 \\
\hline Treonina Total (\%) & 0,862 & 0,854 & 0,849 & 0,778 & 0,777 \\
\hline Valina Total $(\%)$ & 1,056 & 1,050 & 1,048 & 0,961 & 0,903 \\
\hline
\end{tabular}


O arraçoamento foi realizado duas vezes ao dia (07h00min e 17h00min), sendo a ração e a água fornecidas à vontade.

A apanha dos ovos foi realizada diariamente pela manhã. Nos dois últimos dias de cada ciclo, os ovos de cada parcela foram coletados e pesados em balança com precisão de $0,01 \mathrm{~g}$, para obtenção do peso médio. Em seguida, os ovos foram encaminhados para a avaliação da gravidade específica por imersão em baldes com diferentes soluções salinas $(\mathrm{NaCl})$, cujas densidades variaram de 1,050 a 1,100, com intervalos de 0,005.

Para as demais análises, os três ovos mais homogêneos de cada parcela foram selecionados e quebrados. A gema foi separada e com a ajuda do leque de escore colorimétrico DSM ${ }^{\circledR}$ foi verificada sua coloração e pesada, para determinação da percentagem de gema no ovo. As cascas dos ovos foram mantidas identificadas, secas ao ar e posteriormente pesadas e medidas com paquímetro, obtendo-se assim a percentagem e espessura de casca. A percentagem de albúmen foi determinada através da diferença entre o peso do ovo e de suas partes.

Para obtenção da massa de ovos, foi utilizada a produção de ovos postos/ave/dia, multiplicando-se pelo peso médio dos ovos. A conversão alimentar foi calculada de duas maneiras diferentes: dividindo-se o consumo médio diário de ração pela produção média diária em dúzias de ovos (conversão g/dz), e dividindo-se o consumo médio de ração pela massa de ovos (conversão g/g).

Os resultados foram submetidos à análise de variância utilizando-se o procedimento GLM (General Linear Models) do programa SAS (SAS Institute, 1999). Quando significativo ( $\mathrm{P}>0,05)$, foi realizado análise de regressão, possibilitando o melhor nível de inclusão da raspa de mandioca a ser estimado por meio de equações de regressão, respeitando-se a interpretação biológica das variáveis.

A análise econômica foi realizada de acordo com metodologia descrita por Lana (2000) considerando as seguintes variáveis: produção de ovos, consumo de ração e custos das rações. Assim, a análise econômica relaciona-se aos componentes de produção e alimentação, haja vista que a mão de obra e outros gastos com a criação das codornas foram iguais para todos os tratamentos.

O preço médio dos ovos referente ao valor de varejo e os valores de matérias-primas utilizados para o cálculo dos custos das rações foram referente aos valores vigentes no mercado local no período da execução do experimento (julho 2012). O preço do ovo de codorna fornecido pelo produtor em Arapiraca foi de $\mathrm{R} \$$ 0,08/ovo (Tabela 2).

Tabela 2. Preços dos ingredientes ( $\mathrm{R} \$ / \mathrm{Kg})$, do ovo e custos das rações experimentais.

\begin{tabular}{lcccccc}
\hline \multirow{2}{*}{ Ingredientes } & Valor & \multicolumn{5}{c}{ Níveis de inclusão RM (\%) } \\
\cline { 2 - 6 } & $(\mathrm{R} \$ / \mathrm{kg})$ & 0 & 6 & 12 & 18 & 24 \\
\hline Milho & 0,57 & 28,24 & 24,17 & 19,94 & 20,94 & 16,64 \\
Farelo de Soja & 1,32 & 51,98 & 52,79 & 53,91 & 43,86 & 45,78 \\
Raspa da Mandioca & 0,25 & 0,00 & 1,50 & 3,00 & 4,50 & 6,00 \\
Fosfato Bicálcico & 2,18 & 2,29 & 2,14 & 2,15 & 2,25 & 2,32 \\
Calcário & 0,27 & 1,76 & 1,77 & 1,76 & 1,75 & 1,74 \\
Óleo de Soja & 2,5 & 5,3 & 6,81 & 8,45 & 7,5 & 7,5 \\
Sal Comum & 0,4 & 0,12 & 0,12 & 0,12 & 0,12 & 0,12 \\
DL-Metionina & 9,92 & 3,84 & 3,97 & 4,08 & 4,96 & 4,96 \\
Premix Vit. Postura & 6,11 & 0,61 & 0,61 & 0,61 & 0,61 & 0,61 \\
Premix Min. Aves & 4,99 & 0,25 & 0,25 & 0,25 & 0,25 & 0,25 \\
Cloreto de Colina & 3,28 & 0,13 & 0,13 & 0,13 & 0,13 & 0,13 \\
L-Lisina HCL & 5,87 & 0,13 & 0,09 & 0 & 0,81 & 1,31 \\
B H T & 12,51 & 0,13 & 0,13 & 0,13 & 0,13 & 0,13 \\
L-Treonina & 5,99 & 0 & 0 & 0 & 0 & 0,29 \\
Preço do ovo & 0,08 & - & - & - & - & - \\
Total R\$/100kg & - & 94,78 & 94,46 & 94,52 & 87,8 & 87,78 \\
\hline
\end{tabular}

O preço de aquisição da raspa da mandioca foi estimado em R\$ 0,25/kg, levando-se em consideração os custos de mão de obra, de colheita, secagem e transporte.
Para obtenção das variáveis utilizadas na análise econômica, foram considerados: a renda bruta (RB), que é o montante recebido em função do peso vivo versus o preço do frango, a margem bruta 
(MB) que representa a diferença entre a renda bruta e o custo com arraçoamento, a margem bruta relativa (MBR), que é o quociente entre a margem bruta dos demais tratamentos em relação ao tratamento com $0 \%$ de raspa de mandioca (ração basal), a rentabilidade média (RM) que é o valor obtido pela divisão entre a MB e o custo com arraçoamento, indicando a rentabilidade sobre $\mathrm{o}$ investimento em ração e o índice de rentabilidade relativo (IRR), que representa o quociente entre a rentabilidade média dos diversos tratamentos em relação ao tratamento testemunha $(0 \% \mathrm{RM})$. Foi atribuído o valor 100 à margem relativa e ao índice relativo de rentabilidade do tratamento testemunha.

\section{RESULTADOS E DISCUSSÃO}

A inclusão da raspa de mandioca proporcionou comportamento quadrático para consumo de ração $(\mathrm{P}<0,05)$ e conversão alimentar por dúzia de ovos $(0,05<\mathrm{P}<0,10)$. No entanto, não se observou efeito dos tratamentos sobre a conversão alimentar por massa de ovo $(\mathrm{g} / \mathrm{g})$ e nem da percentagem de postura das aves (Tabela 3 ).

Tabela 3. Consumo de ração (CR), conversão alimentar (CA) e percentagem de postura de codornas alimentadas com ração contendo raspa da mandioca $(\mathrm{RM})$.

\begin{tabular}{|c|c|c|c|c|c|c|c|c|}
\hline \multirow{2}{*}{ Variáveis } & \multicolumn{5}{|c|}{ Níveis de RM (\%) } & \multirow[b]{2}{*}{ Equação } & \multirow[b]{2}{*}{$\mathrm{R} 2$} & \multirow[b]{2}{*}{$\mathrm{CV}(\%)$} \\
\hline & 0 & 6 & 12 & 18 & 24 & & & \\
\hline CR (g/ave/dia) & 27,84 & 29,21 & 30,45 & 29,74 & 26,33 & $1 * *$ & 0,94 & 4,35 \\
\hline $\mathrm{CA}(\mathrm{g} / \mathrm{dz})$ & 360,80 & 374,24 & 388,54 & 370,43 & 333,98 & $2 *$ & 0,96 & 4,68 \\
\hline $\mathrm{CA}(\mathrm{g} / \mathrm{g})$ & 2,57 & 2,61 & 2,70 & 2,66 & 2,41 & $\hat{\mathrm{Y}}=2,61$ & - & 6,27 \\
\hline Postura (\%) & 89,35 & 93,55 & 93,99 & 96,09 & 90,94 & $\hat{\mathrm{Y}}=93,55$ & - & 5,45 \\
\hline
\end{tabular}

** Efeito quadrático $(\mathrm{P}<0,05)$. * Efeito quadrático $(0,05<\mathrm{P}<0,10)$. $\mathrm{CV}=$ Coeficiente de variação. ${ }^{1} \hat{\mathrm{Y}}=27,58$ $+0,50 \mathrm{x}-0,02 \mathrm{x}^{2} ;{ }^{2} \hat{\mathrm{Y}}=358,23+5,32 \mathrm{x}-0,26 \mathrm{x}^{2}$.

Em relação ao consumo, é provável que o maior nível de amido solúvel da raspa da mandioca, em comparação com o grão de milho, tenha aumentado a glicemia da ave e proporcionado efeito depressor sobre o consumo de ração. Cruz et al. (2006) e Raphaël et al. (2013) também observaram efeito quadrático da inclusão da raspa de mandioca sobre o consumo de ração de galinhas poedeiras.

A influência do aumento do nível de mandioca na dieta sobre a conversão alimentar por dúzia de ovos pode ter pode ter ocorrido em virtude da ausência de diferença sobre a produção de ovos entre os tratamentos mesmo com diferenças consistentes no consumo de ração das aves. É recorrente na literatura que a inclusão de níveis superiores a $10 \%$ de subprodutos da mandioca provoca piora na conversão alimentar das aves (Nascimento et al., 2005; Costa et al., 2009; Ferreira et al., 2012; Ferreira et al., 2014).

A inclusão da raspa da mandioca não influenciou $(\mathrm{P}>0,05)$ as características de qualidade do ovo (Tabela 4).

Tabela 4. Qualidade do ovo de codornas alimentadas com ração contendo raspa da mandioca (RM).

\begin{tabular}{|c|c|c|c|c|c|c|c|c|}
\hline \multirow{2}{*}{ Variáveis } & \multicolumn{5}{|c|}{ Níveis RM (\%) } & \multirow[b]{2}{*}{ Equação } & \multirow[b]{2}{*}{ R2 } & \multirow[b]{2}{*}{$\mathrm{CV}(\%)$} \\
\hline & 0 & 6 & 12 & 18 & 24 & & & \\
\hline Albúmen (\%) & 61,23 & 61,34 & 61,19 & 61,01 & 62,03 & $\hat{\mathrm{Y}}=61,23$ & - & 1,85 \\
\hline Gema $(\%)$ & 30,78 & 30,75 & 30,89 & 30,83 & 29,81 & $\hat{\mathrm{Y}}=30,78$ & - & 3,04 \\
\hline Casca $(\%)$ & 7,97 & 7,90 & 7,91 & 8,15 & 8,15 & $\hat{\mathrm{Y}}=7,97$ & - & 3,61 \\
\hline $\mathrm{CG}$ & 3,49 & 3,49 & 3,33 & 3,36 & 3,28 & $\hat{Y}=3,36$ & - & 4,83 \\
\hline PO (g) & 12,13 & 12,03 & 12,03 & 11,64 & 10,84 & $1^{*}$ & 0,77 & 7,15 \\
\hline GE (g/L) & 1,074 & 1,073 & 1,073 & 1,075 & 1,076 & $\hat{\mathrm{Y}}=1,074$ & - & 0,22 \\
\hline $\mathrm{EC}(\mathrm{cm})$ & 0,193 & 0,191 & 0,194 & 0,195 & 0,193 & $\hat{\mathrm{Y}}=0,193$ & - & 3,47 \\
\hline
\end{tabular}

CV= Coeficiente de variação. CG: cor da gema; PO: peso do ovo; GE: gravidade específica; EC: espessura de casca. * Efeito linear $(0,05<\mathrm{P}<0,10) .{ }^{1} \hat{\mathrm{Y}}=12,328-0,0495 \mathrm{x}$.

Os parâmetros de qualidade do ovo não diferiram entre os tratamentos $(\mathrm{P}>0,05)$ e apresentaram-se próximos ao documentados por Guimarães et al. (2014) para codornas japonesas. A ausência de diferença sobre os parâmetros de qualidade do ovo pode ser atribuída a similaridade da matriz nutricional das dietas experimentais. Exceto para cor de gema, Moura et al. (2010) também não encontraram efeito da inclusão de uma fonte alternativa de amido na dieta sobre a qualidade do ovo de codornas japonesas. 
Devido à deficiência em carotenoides na raiz da mandioca (Chauynarong et al., 2009), era esperado uma redução no escore de coloração da gema. Esse efeito não foi verificado, o que nos leva a inferir que a quantidade de carotenoides da ração, mesmo com nível mais alto de inclusão da raspa de mandioca, foi suficiente para promover coloração da gema.

Observou-se uma tendência a comportamento linear negativo $(0,05<\mathrm{P}<0,10)$ para peso do ovo, em que para cada $1 \%$ de inclusão de raspa o peso do ovo foi reduzido em $0,05 \mathrm{~g}$. É provável que o efeito sobre o consumo de ração tenha influenciado negativamente a quantidade de metabólitos disponíveis para formação do ovo, provocando redução no peso do mesmo. O peso do ovo de poedeiras também foi reduzido quando o milho foi substituído por raspa de mandioca (Anaeto \& Adighibe, 2011).

Os valores do custo com arraçoamento foram menores no tratamento com $24 \%$ de inclusão da raspa da mandioca, indicando que houve economia de $\mathrm{R}$ \$ 0,01 por ave com alimentação em relação ao tratamento referência (Tabela 5). Cruz et al. (2006) observaram redução no custo por $\mathrm{kg} / \mathrm{ração} \mathrm{com} \mathrm{a}$ inclusão da raspa da mandioca na alimentação de poedeiras.

Tabela 5. Análises das variáveis econômicas da produção de ovos de codornas alimentadas com raspa da mandioca.

\begin{tabular}{lccccc}
\hline \multirow{2}{*}{ Variáveis } & \multicolumn{5}{c}{ Níveis de RPM (\%) } \\
\cline { 2 - 6 } & 0 & 6 & 12 & 18 & 24 \\
\hline Custo do arraçoamento (R \$ave) & 0,51 & 0,56 & 0,59 & 0,54 & 0,50 \\
Renda bruta (R\$/ave) & 3,03 & 3,02 & 3,06 & 3,14 & 3,00 \\
Margem bruta (R\$/ave) & 2,52 & 2,46 & 2,46 & 2,60 & 2,50 \\
Margem bruta relativa (\%) & 100,00 & 97,46 & 97,67 & 102,97 & 99,02 \\
Rentabilidade média (\%) & 496,95 & 438,76 & 415,18 & 479,59 & 526,05 \\
Índice de rentabilidade relativo (\%) & 100,00 & 88,29 & 83,55 & 96,51 & 105,86 \\
\hline
\end{tabular}

No entanto, a maior renda bruta foi obtida com o tratamento com $18 \%$ de inclusão da raspa da mandioca na ração, representando um ganho de $\mathrm{R} \$$ 0,11 por aves em comparação com o tratamento referência.

A margem bruta foi superior para o tratamento com $18 \%$ de inclusão em relação aos demais tratamentos, sendo 2,97\% acima da ração controle. Semelhantemente, Costa et al. (2009) obtiveram um aumento de 4,5\% na margem bruta relativa com a inclusão de $15 \%$ de raspa da mandioca na ração de poedeiras semipesadas.

A rentabilidade média no tratamento com $0 \%$ de raspa de mandioca foi $496,95 \%$, enquanto que, naquele com nível máximo de inclusão (24\%) foi de $526,05 \%$. A pior rentabilidade foi encontrada nas criações em que as codornas receberam $12 \%$ de rasda de mandioca.

\section{CONCLUSÃO}

Recomenda-se a inclusão de até $12 \%$ de raspa de mandioca na ração de codornas em postura. Níveis mais elevadas (18 e 24\%) promovem aumento do consumo de ração, piora na conversão alimentar e redução do peso do ovo.

\section{REFERÊNCIAS}

ANAETO, M.; ADIGHIBE, L.C. Cassava root meal as substitute for maize in layers ration. Brazilian Journal Poultry Science, v.13, n.2, p.153-156, 2011.

CHAUYNARONG, N.; ELANGOVAN, A.V.; IJI, P.A. 2009 The potential of cassava products in diets for poultry. World's Poultry Science Journal, v.65, n.3, p.23-36, 2009.

COSTA, F.G.P. et al. Desempenho, qualidade de ovos e análise econômica da produção de poedeiras semipesadas alimentadas com diferentes níveis de raspa de mandioca. Acta Scientiarum. Animal Science. v.31, n.1, p.13-18, 2009.

CRUZ, F. G. G.; PEREIRA FILHO, M.; CHAVES, F. A. L. Efeito da substituição do milho pela farinha da apara de mandioca em rações para poedeiras comerciais. Revista Brasileira de Zootecnia, v.35, n.6, p.2303-2308, 2006.

FERREIRA, A. H. C. et al. Raspa integral da raiz de mandioca para frangas de um a 42 dias de idade. Revista Brasileira de Saúde e Produção Animal, v.13, n.1, p.160-172, 2012.

FERREIRA, A. H. C. et al. Whole scrapings of cassava root in diets for broilers from 1 to 21 days of age. Acta Scientiarum. Animal Science. v.36, n.4, p.357-362, 2014.

GUIMARÃES, M. C. C. et al. Efeito da estação do ano sobre o desempenho produtivo de codornas no semiárido paraibano. Revista Brasileira de Engenharia Agrícola e Ambiental, v.18, n.2, p.231-237, 2014.

LANA, G. R. Q. Avicultura. Ed. Rural. Recife: UFRPE, 237p. 2000 . 
MOURA, A. M. A. et al. Desempenho e qualidade do ovo de codornas japonesas alimentadas com rações contendo sorgo. Revista Brasileira de Zootecnia, v.39, n.2, p.2697-2702, 2010.

NASCIMENTO, G. A. J. et al. Efeitos da substituição do milho pela raspa de mandioca na alimentação de frangos de corte, durante as fases de engorda e final. Ciência e Agrotecnologia, v.29, n.1, p.200-207, 2005.

RAPHAËL, K. J. et al. Effect of substituting maize with cassava root meal on laying performances of local barred-chicken under improved management conditions in Cameroon. Livestock Research Rural Development. v.25, n.10, p.1-7, 2013.

ROSTAGnO, H.S., ALBINO, L.F.T., DONZELE, J.L. Tabelas brasileiras para aves e suínos: composição de alimentos e exigências nutricionais. $3^{\mathrm{a}}$ ed. Viçosa, MG: Universidade Federal de Viçosa. 252 p. 2011.

SAS INSTITUTE. SAS/STAT User's Guide, Version 7-1, Cary, NC.1991.

SILVA, J. H. V. et al. Energia metabolizável de ingredientes determinada com codornas japonesas (Coturnix coturnix japonica). Revista Brasileira de Zootecnia, v.32, n.6, p.19121918, 2003.

SILVA, J. H. V. et al. Exigências nutricionais de codornas. Revista Brasileira de Saúde e Produção Animal, v.13, n.3, p.775-790, 2012. 